\title{
Produção e qualidade da forragem de capim-marandu fertiirrigada com dejetos líquidos de suínos ${ }^{1}$
}

\author{
Lucilene Tavares Medeiros ${ }^{2}$, Adauton Vilela de Rezende ${ }^{3}$, Paulo de Figueiredo Vieira ${ }^{3}$, \\ Francisco Rodrigues da Cunha $\mathrm{Neto}^{3}$, Alexandre Rocha Valeriano ${ }^{4}$, André Oliveira Casali ${ }^{5}$, \\ Adilson Luis Gastaldello Junior6
}

\footnotetext{
1 Parte da Dissertação da primeira autora.

2 Mestranda em Ciência Animal da UNIFENAS. Bolsista da CAPES.

${ }^{3}$ Faculdade de Ciências Agrárias/UNIFENAS - Alfenas-MG.

${ }^{4}$ Graduando em Agronomia/UNIFENAS. Bolsista CNPq/PIBIC.

5 Graduando em Zootecnia/UNIFENAS. Bolsista CNPq/PIBIC.

${ }^{6}$ Graduando em Zootecnia/UNIFENAS.
}

RESUMO - Esta pesquisa foi realizada com o objetivo de avaliar os efeitos da fertilização com dejetos líquidos de suínos (DLS) nas características agronômicas e bromatológicas da forragem de capim-marandu. Foram avaliados a produtividade de MS, o perfilhamento, o percentual de MS, PB, FDN e FDA e a digestibilidade in vitro da MS (DIVMS). Adotou-se o delineamento em blocos casualizados, com nove tratamentos (adubações) e quatro repetições. Os tratamentos são descritos a seguir: T1 - uso de calcário; T2 - adubação com 100, 40 e $60 \mathrm{~kg} / \mathrm{ha}$ de N P K; T3 - $180 \mathrm{~m}^{3}$ de DLS/ha 1x/ano; T4 $180 \mathrm{~m}^{3} \mathrm{de}$ DLS/ha 2x/ano); T5 - $180 \mathrm{~m}^{3}$ de DLS/ha 3x/ano; T6 - $180 \mathrm{~m}^{3} \mathrm{de}$ DLS/ha 4x/ano; T7 - $180 \mathrm{~m}^{3} \mathrm{de} \mathrm{DLS/ha} \mathrm{5x/}$ ano; T8 - $180 \mathrm{~m}^{3}$ de DLS/ha 1x/ano (in natura); T9 (testemunha) - fermentação do DLS utilizado nos tratamentos 1,2 , 8 e 9 por, no mínimo, 45 dias. As médias foram comparadas pelo teste Scott-Knott. Na calagem, utilizou-se alcário dolomítico na proporção de $3 \mathrm{t} / \mathrm{ha}$ e, na adubação química, 100, 40 e $60 \mathrm{~kg} / \mathrm{ha}$ de $\mathrm{N}, \mathrm{P}_{2} \mathrm{O}_{5}$ e $\mathrm{K}_{2} \mathrm{O}$ nas formas de sulfato de amônia supersimples e cloreto de potássio. Os cortes foram realizados a cada 45 dias. O número de perfilhos $/ \mathrm{m}^{2}$, a produtividade de MS e a qualidade da forrageira foram maiores com a utilização de DLS em dose única nos primeiros cortes. As forrageiras dos tratamentos 3, 4, 8 e 9 apresentaram maiores teores de PB nos primeiros cortes, com médias de 9,6 a 13,7\%. Os maiores teores de FDN foram obtidos no segundo corte (médias de 61,4 a 68,6\%) e os menores de FDA foram encontrados com DLS 2x/ano e 5x/ano no primeiro corte (médias de 21,2 a 23,4\%). Os tratamentos 3 , 4 e 8 proporcionaram os maiores coeficientes de DIVMS no primeiro corte, com médias de 69,0 a 71,8\%.

Palavras-chave: adubação orgânica, época de corte, perfilhamento, valor nutritivo

\section{Forage yield and quality of marandugrass as affected by fertiirrigation with swine slurry}

\footnotetext{
ABSTRACT - The objective of this research was to evaluate swine slurry (SS) application on the agronomic and bromatologic characteristics of marandugrass. The following response variables were determined: DM productivity, tillering, concentrations of DM, CP, NDF, and ADF, and in vitro DM digestibility (IVDMD). It was used a randomized block design with nine treatments (fertilization) and four replications. Treatments were described as follows: T1 (liming); T2 (chemical fertilization - 100, 40 e $60 \mathrm{~kg} / \mathrm{ha}$ of $\left.\mathrm{N}_{2} \mathrm{O}_{5} \mathrm{~K}_{2} \mathrm{O}\right)$; T3 (180 m³/ha of SS 1x/year - fermented for 45 days);

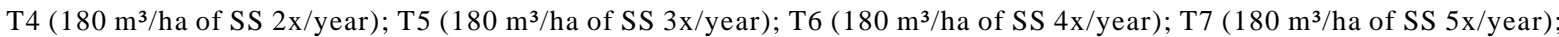
T8 $\left(180 \mathrm{~m}^{3} / \mathrm{ha}\right.$ of SS $1 \mathrm{x} / \mathrm{year}$ - in natura); T9 (control). Means were compared using the Scott-Knott test. The liming was accomplished applying three metric tons of dolomitic limestone. Sources of nutrients in the chemical fertilization included ammonium sulphate, single superphosphate, and potassium chloride. Cuts were performed every 45 days. A single application of swine slurry (SS) promoted greater number of tillers $/ \mathrm{m}^{2}$, greater DM accumulation, and better forage nutritive value for initial harvestings. Greater values of $\mathrm{CP}$ were found in treatments 3, 4, 8, and 9 during initial harvestings. The CP means ranged from 9.6 to $13.7 \%$. The NDF concentration was greater at the second cut and NDF means ranged from 61.4 to $68.6 \%$. The ADF concentration was lower at the first cut when SS was applied twice and five times per year. The ADF means ranged from 21.2 to $23.4 \%$. The greatest IVDMD occurred at the first cut in treatments 3,4 and 8 and IVDMD means ranged from 69.0 to $71.8 \%$.
}

Key Words: cutting time, nutritional value, organic manuring, tillering 


\section{Introdução}

O Brasil tem vasta área de pastagens e condições edafoclimáticas favoráveis ao desenvolvimento das plantas forrageiras e pastagens, entretanto, estatísticas têm revelado um quadro de degradação. Conseqüentemente, o valor nutritivo e a capacidade de recuperação destas plantas forrageiras diminuem, aumentando os efeitos erosivos no solo.

A suinocultura brasileira está crescendo de forma significativa, ocasionando elevada concentração de resíduos orgânicos de forma localizada. Esses resíduos, quando utilizados de forma inadequada, podem trazer sérios prejuízos ambientais, todavia, se utilizados racionalmente, podem se tornar uma boa alternativa para adubação de forrageiras. Neste sentido, objetivou-se verificar a melhor freqüência de aplicações de DLS e os efeitos dessa adubação nas características bromatológicas e agronômicas de pastagens de capim-marandu (Brachiaria brizantha cv. Marandu).

Barnabé (2001), avaliando a fertirrigação de capimmarandu com dejetos líquidos de suínos, observou teores médios (na MS) de 23,12 a 25,8\% de MS; 7,6 a 9,8\% de PB; 69,5 a 72,7\% de FDN e 36,9 a 38,8 de FDA no corte a cada 33 dias. Nesta mesma pesquisa, foi realizada adubação química com 50, 100 e $150 \mathrm{~m}^{3}$ de DLS/ha e o autor observou que a aplicação de $150 \mathrm{~m}^{3}$ de DLS em substituição à adubação química foi a que promoveu os melhores resultados. Em pesquisa realizada com $B$. brizantha submetida a intervalos de cortes durante as estações do ano, Mari (2003) observou efeitos das estações sobre o teor de MS, que foi maior no inverno (26,6\%), seguido do outono e da primavera (24,6\% cada). As variações nos teores médios de PB foram de 8,9 a 13,3\%; FDN, 66,8 a 70,4\%; e na DIVMS, de 62,3 a 67,4\% nos intervalos dos cortes durante as estações do ano. Em relação às estações do ano, Gerdes et al. (2000a), estudando a B. brizantha, observaram que os teores de MS no verão e no inverno foram maiores que na primavera e no outono, variando de 20,17 a 27,6\%.

Diversos pesquisadores (Drudi \& Favoretto, 1987; Lavezzo et al., 1980; Nunes et al., 1985; Rolim, 1976) demonstraram que, conforme se distanciam os cortes, os teores de MS tendem a aumentar.

Segundo Langer, (1972), citado por Gomide et al. (2003), os fatores que mais afetam o perfilhamento de uma forrageira são o genótipo, o florescimento, a nutrição mineral (em especial $\mathrm{N}$ interagido com $\mathrm{P}$ e K, por favorecer o aumento populacional de perfilhos) e o manejo de cortes e elementos de clima, como luz, temperatura, fotoperíodo e disponibilidade hídrica.
Estudando o comportamento do capim-marandu sob alturas de corte, Lupinacci (2002) e Sbrissia (2004) observaram que pastagens mantidas a $10 \mathrm{~cm}$ apresentaram aumento na proporção de plantas invasoras, na depleção de reservas orgânicas (C e N) e na produção de MS/ha, demonstrando ser instável para as plantas. Entretanto, a produção MS/ha praticamente não diferiu entre as demais alturas (20,30 e $40 \mathrm{~cm}$ ), obtendo-se média de $26 \mathrm{t} \mathrm{MS} / \mathrm{ha}$. Os dois autores observaram também compensação entre o número e o tamanho de perfilhos, de modo que pastagens mais baixas tiveram maior densidade populacional de perfilhos pequenos e apresentaram menor densidade populacional de perfilhos grandes. Entretanto, Zago \& Gomide (1982) afirmaram que a maior frequiência de corte reduziu a produção de MS, como resultado da decapitação de numerosos perfilhos, determinando a redução de reservas e comprometendo a rebrotação. Rosa et al. (2004), trabalhando com B. brizantha, utilizaram $200 \mathrm{~m}^{3}$ de DLS/ha/ano e obtiveram 2,8 t/ha de MS, enquanto Barnabé (2001), também em B. brizantha no período de 14/12/99 a 23/ 04/00, observou máximo de $6,3 \mathrm{t}$ de $\mathrm{MS} / \mathrm{ha}$ quando utilizou $150 \mathrm{~m}^{3}$ de DLS/ha/ano e três cortes.

\section{Material e Métodos}

O experimento foi realizado na Fazenda do Barreiro (propriedade particular), município de Alfenas-MG, em um Latossolo vermelho distrófico típico Vermelho, com declividade de $8 \%$, ocupado com pastagem de B. brizantha cv Marandu estabelecida há sete anos, atualmente em estado de degradação. O município de Alfenas localiza-se nas coordenadas geográficas de $21^{\circ} 25^{\prime}$ de latitude (S) e $45^{\circ} 57^{\prime}$ de longitude (W), com altitude média de $880 \mathrm{~m}$, temperatura de 18 a $23^{\circ} \mathrm{C}$ e precipitação média anual de $1.800 \mathrm{~mm}$, e possui clima subtropical úmido.

Em agosto de 2003, delimitou-se a área experimental e realizaram-se amostragens do solo para caracterização química e física. De acordo com os resultados das análises, o solo possui as seguintes características: $\mathrm{pH}-5,1 ; \mathrm{P}-1,2$; $\mathrm{K}-44\left(\mathrm{mg} / \mathrm{dm}^{3}\right) ;\left[\mathrm{Ca}^{2+} 0,8 ; \mathrm{Mg}^{2+} 0,7 ; \mathrm{Al}^{3+} 0,8 ; \mathrm{H}+\mathrm{Al} 5,0\right.$; SB 1,6; t2,4; T 6,6; V 24,5 (cmol/ $\left.\left./ \mathrm{dm}^{3}\right)\right] ; \mathrm{m} 33 \%$ e textura argilosa. Considerando os resultados das análises, realizou-se a calagem em todas as parcelas do experimento, visando elevar a saturação de bases a $65 \%$. Efetuou-se aplicação de calcário dolomítico com PRNT de $85 \%$ no nível de $3 \mathrm{t} / \mathrm{ha}$. A calagem foi realizada a lanço, sem incorporação, no dia 29/08/2003.

No dia 06/10/2003, foi realizado corte de uniformização a aproximadamente $5 \mathrm{~cm}$ da superfície utilizando-se roçadeira costal e, em seguida, todo o material cortado foi retirado da área. 
Foram testados os seguintes tratamentos: T1 - uso somente de calcário; T2 - adubação química com 100, 40 e 60 de NPK; T3 - $180 \mathrm{~m}^{3}$ de DLS/ha 1x/ano; T4 - $180 \mathrm{~m}^{3} \mathrm{de}$ DLS/ha 2x/ano; T5 - $180 \mathrm{~m}^{3}$ de DLS/ha 3x/ano; T6 - $180 \mathrm{~m}^{3}$ de DLS/ha 4x/ano; T7 - $180 \mathrm{~m}^{3}$ de DLS/ha 5x/ano; T8 - $180 \mathrm{~m}^{3}$ de DLS/ha 1x/ano (in natura); T9 (controle) - sem correção e adubação. Os dejetos utilizados foram submetidos à fermentação por 45 dias, à exceção do tratamento 8 , no qual foram aplicados in natura.

A primeira aplicação foi realizada imediatamente após o corte de uniformização, no dia $06 / 10 / 03$, quando foram aplicados todos os tratamentos propostos; as demais aplicações obedeceram à divisão dos tratamentos, com a distribuição dentro dos meses que compreenderam o período experimental (um ano) e suas freqüências de distribuição/ ano. Oprimeiro corte da planta foi realizado 45 dias após a primeira aplicação dos tratamentos, ou seja, no dia 20/11/03, quando foi aplicado o tratamento T7, com aplicação de DLS 5 vezes ao ano. O segundo corte foi realizado no dia 04/01/04 e, nesse mesmo dia, aplicaram-se os tratamentos T6 e T7 (aplicação de DLS 4 e 5 vezes ao ano, respectivamente). O terceiro corte, previsto para o dia 18/02/04, não foi possível, pois a planta apresentava-se com baixo desenvolvimento vegetativo, porém, nesta mesma data (18/02/04), foram aplicados os tratamentos T4, T5, T6 e T7 (aplicação de DLS 2, 3, 4 e 5 vezes ao ano, respetivamente). O quarto corte foi realizado em 03/04/04 (não houve nenhum tratamento previsto para essa data) e o quinto, em 18/05/04, quando foram aplicados os tratamentos T5, T6 e T7 (aplicação de DLS 3, 4 e 5 vezes ao ano). O sextocorte, previsto para 02/07/04, também não foi possível, pois a planta apresentava baixo desenvolvimento vegetativo. Assim, os cortes foram realizados a cada 45 dias a partir da data da primeira aplicação dos dejetos.

A área experimental constituiu-se de quatro blocos de nove parcelas. A área das parcelas foi de $12 \mathrm{~m}^{2}(4 \times 3 \mathrm{~m})$, com $0,5 \mathrm{~m}$ de bordadura, totalizando $782 \mathrm{~m}^{2}$. Após o corte de uniformização da planta forrageira, a adubação química foi realizada a lanço e em cobertura, uma única vez, com 100, 40 e $60 \mathrm{~kg} / \mathrm{h}$ a de N P K, respectivamente, nas formas de sulfato de amônio, superfosfato simples e cloreto de potássio, considerando as exigências da cultura e as recomendações do CFSEMG (1999).

Os dejetos líquidos de suínos foram colhidos de tanque impermeabilizado com cimento, de uma suinocultura que trabalha com todas as fases da criação (a $21 \mathrm{~km} \mathrm{da}$ UNIFENAS, em Alfenas - MG, a 1,5 km da área experimental), e foram distribuídos manualmente utilizando-se regadores. Os dejetos foram colhidos do tanque de deposição por um trator com auxílio de uma bomba de sucção, succionados e devolvidos para o tanque de recepção por duas vezes consecutivas, visando maior homogeneização do material. Esta operação foi repetida em todas as retiradas dos dejetos. Os dejetos foram levados à área experimental e depositados em caixas de amianto revestidas com lona preta, onde permaneceram por, no mínimo, 45 dias para fermentação antes da utilização nas parcelas.

As amostras de forragem foram colhidas em quatro locais dentro de cada parcela utilizando-se um quadrado com $0,25 \mathrm{~m}^{2}(0,5 \times 0,5 \mathrm{~m})$. O corte foi feito manualmente a $5 \mathrm{~cm}$ da superfície do solo e, após a retirada das amostras, foi realizado corte total das plantas nas parcelas.

A contagem de perfilhos foi realizada antes do quarto corte, em maio de 2004, utilizando-se um quadrado com $0,25 \mathrm{~m}^{2}(0,5 \times 0,5 \mathrm{~m})$ lançado em quatro locais de cada parcela para obtenção de uma amostra significativa, com base na média das quatro repetições.

As porcentagens de MS e PB foram determinadas conforme técnicas da Association of Official Analytical Chemists - AOAC, descritas por Horwtzs (1975). Os teores de FDN e FDA foram obtidos utilizando-se o método descrito por Goering \& Van Soest (1970). A digestibilidade in vitro da MS foi determinada de acordo com o método das duas etapas de Tilley \& Terry, citado por Silva (2002).

$\mathrm{O}$ delineamento experimental utilizado foi o de blocos completos e casualizados, com nove tratamentos e quatro repetições, em esquema de parcela subdividida no tempo. As parcelas foram compostas pelos tratamentos (freqüência de aplicação de dejetos) e as subparcelas, pelas épocas de amostragem da forragem. Utilizou-se o programa SISVAR (Ferreira, 2000) para análises estatísticas e, para comparação das médias, aplicou-se o teste Scott - Knott a 1 e 5\%.

\section{Resultados e Discussão}

$\mathrm{Na}$ análise da densidade populacional de perfilhos, observou-se que as plantas dos tratamentos 3 e 8 (DLS fermentado por 45 dias e in natura, respectivamente $180 \mathrm{~m}^{3} / \mathrm{ha} / \mathrm{ano}$ ) apresentaram maior número de pefilhos (Tabela 1). Este resultado pode ter sido ocasionado pela maior disponibilidade de nutrientes no solo e pelas boas condições climáticas no período.

Em estudo realizado por Langer, citado por Gomide et al. (2003), os fatores que mais afetaram o perfilhamento de gramíneas foram genótipo, fatores climáticos e nutrição mineral, especialmente na forma nitrogenada, que interagiram com a maior absorção de fósforo e potássio, favorecendo a produção de perfilhos. 
Tabela 1 - Densidade populacional de perfilhos $/ \mathrm{m}^{2}$ de capimmarandu fertirrigado com dejetos líquidos de suínos

Table 1 - Tiller density (number of tillers $/ \mathrm{m}^{2}$ ) of Brachiaria brizantha $\mathrm{cv}$ Marandu fertirrigated with swine slurry

\begin{tabular}{lc}
\hline $\begin{array}{l}\text { Tratamento } \\
\text { Treatment }\end{array}$ & $\begin{array}{c}\text { Média } \\
\text { Average }\end{array}$ \\
\hline 1 & $791 \mathrm{C}$ \\
2 & $907 \mathrm{~B}$ \\
3 & $1.180 \mathrm{~A}$ \\
4 & $1.082 \mathrm{~B}$ \\
5 & $992 \mathrm{~B}$ \\
6 & $1.057 \mathrm{~B}$ \\
7 & $991 \mathrm{~B}$ \\
8 & $1.214 \mathrm{~A}$ \\
9 & $568 \mathrm{D}$ \\
\hline
\end{tabular}

Médias seguidas de letras diferentes na coluna diferem $(P<0,05)$ pelo teste Scott-Knott.

Means followed by different letters, in the column differ $(P<0.05)$ by Scott-Knott test.

A menor densidade populacional de perfilhos $/ \mathrm{m}^{2}$ foi obtida com o tratamento testemunha (sem adubação e correção), seguido do tratamento no qual se utilizou somente a calagem. Essa situação provavelmente está associada ao esgotamento de nutrientes no solo, pois a pastagem de B. brizantha apresentava-se em estado de degradação. Nesse sentido, a utilização de dejetos líquidos promoveu resultados positivos e significativos no número de perfilhos.

A densidade populacional de perfilhos $/ \mathrm{m}^{2}$ observada nas plantas dos tratamentos com aplicação de $180 \mathrm{~m}^{3}$ de DLS/ha/ano em dosagem única foi superior à encontrada em experimento realizado por Sbrissia (2004), que observou densidade populacional de $1.069,978,865$ e $692 \mathrm{em}$ pastagem de capim-marandu mantida em quatro alturas de cortes (10, $20,30 \mathrm{e} 40 \mathrm{~cm}$, respectivamente). Esses resultados corroboram informações relatadas pelo mesmo autor, que afirmou que pastagens mais baixas apresentaram maior densidade populacional de perfilhos.
Houve interação tratamento $\times$ época de corte $(\mathrm{P}<0,05)$, sendo obsevado decréscimo da produção a partir do segundo corte (Tabela 2).

Comparando os cortes, houve vantagens significativas nas produções de MS no segundo corte, o que possivelmente foi ocasionado pela maior disponibilidade de nutrientes mineralizados, oriundos dos dejetos de suínos. Além disso, houve mais alta precipitação pluviométrica e maior fotoperíodo.

As maiores produções de MS foram obtidas com os tratamentos 3 e 8 , que proporcionaram, em relação à adubação química, acréscimo de $30 \%$ na produção de MS.

Quando avaliada a interação tratamento $\times$ época de corte (Tabela 2), de modo geral, os menores valores de produção de MS foram observados no quarto corte. No tratamento 9 (testemunha), no entanto, a época de corte não teve efeito significativo sobre a produção de MS. Zago \& Gomide (1982) postularam que a maior freqüência de corte reduz a produção de MS, como resultado da decapitação de inúmeros perfilhos, e que, até a adaptação plástica da comunidade de plantas, a freqüência de corte determina a depleção de reservas e o comprometimento da rebrotação subseqüente.

De modo geral, as produções de MS observadas com aplicação de $180 \mathrm{~m}^{3}$ de DLS/ha/ano em dosagem única foram superiores às encontradas por Rosa et al. (2004), que obtiveram 2,8 t/ha de MS em pastagens de Brachiaria brizantha fertilizadas com $200 \mathrm{~m}^{3}$ de DLS/ha/ano. Barnabé (2001) observou valor de 6,3 t/ha/ano de MS em B. brizantha fertilizada com $150 \mathrm{~m}^{3}$ de DLS/ha/ano, quando realizou três cortes no período de 14/12/99 a 23/ 04/00. Nesta pesquisa, obteve-se valor acumulado de 12,7 t/ha de MS com aplicação única de $180 \mathrm{~m}^{3}$ de DLS/ha/ano entre os meses de novembro/2003 a junho/2004.

Tabela 2 - Produção de MS, em t/ha, em quatro cortes de capim-marandu fertirrigado com dejetos líquidos de suínos Table 2 - DM yield (t/ha) of Brachiaria brizantha cv. Marandu fertirrigated with swine slurry; average data of four cuts

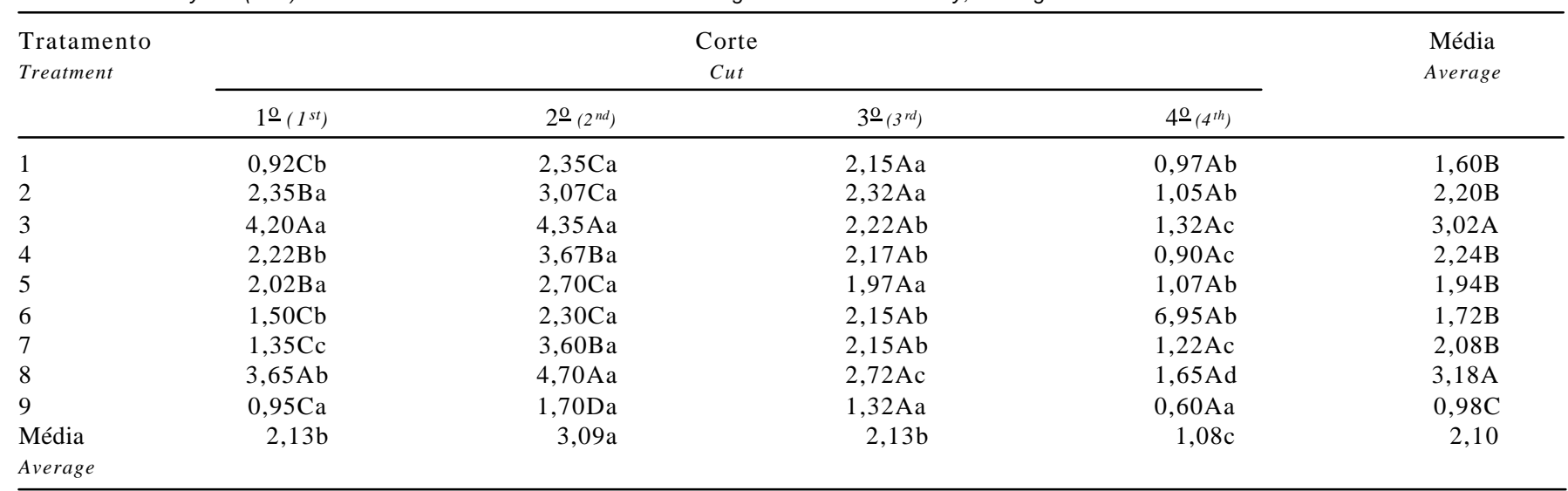


No tratamento no qual se utilizou somente calcário (T1) e no tratamento controle (T9), as plantas apresentaram maiores percentuais de MS no primeiro e terceiro cortes. No segundo e quarto cortes, o tratamento testemunha proporcionou, de forma isolada, maiores percentuais de MS (Tabela 3).

Estes resultados podem ser explicados pela baixa disponibilidade de nutrientes à planta, o que ocasiona senescência precoce. De acordo com Gomide (1994), o percentual de MS das plantas forrageiras pode sofrer interferência de componentes da produção que são afetados pela atividade dos drenos metabólicos e/ou pelo equilíbrio entre produção e perdas. Essas perdas são atribuídas à senescência de folhas, à fotorrespiração, à respiração, à altura de pastejo e ao intervalo de pastejo. Além desses fatores, a insuficiência de nutrientes como $\mathrm{N}$ e $\mathrm{P}$ nas folhas pode contribuir para acelerar o processo de senescência.

De modo geral, os menores teores de MS foram observados nos tratamentos nos quais foram aplicadas as maiores dosagens de DLS no início do período experimental. As diferenças nesses tratamentos (nos tratamentos 3, 5, 6 e 7 com aplicação de DLS uma, três, quatro e cinco vezes ao ano, respectivamente, houve acréscimo nos percentuais de MS somente a partir do terceiro corte) talvez possam ser atribuídas ao maior crescimento vegetativo das plantas e, conseqüentemente, ao maior acúmulo de água na parte aérea da planta forrageira. No entanto, no terceiro corte, os resultados desses tratamentos foram semelhantes aos intermediários e diferiram somente dos otidos nos tratamentos 1 e 9 (uso de calcário e testemunha, respectivamente).

Os maiores percentuais de MS foram registrados no quarto corte e, portanto, os menores teores concentraram-se no primeiro e segundo cortes, independentemente dos tratamentos. As diferenças nos teores de MS entre as épocas de corte provavelmente estão relacionadas ao comportamento fisiológico da planta forrageira, coincidindo com o período favorável do ano, com a maior disponibilidade de nutrientes decorrente dos tratamentos, ocasionando maior desenvolvimento vegetativo. Segundo Hill (1980), a deficiência nutricional da planta, provocada por indisponibilidade de nutrientes no solo e/ou da não absorção pelo sistema radicular, pode acelerar a senescência das folhas pela translocação de elementos como $\mathrm{N}$ e $\mathrm{P}$ para as folhas mais novas. Nesta pesquisa, verificou-se comportamento semelhante da planta forrageira.

As maiores porcentagens de MS observadas no mês de abril (quarta época de corte) podem ser explicadas também pela época do ano, que coincidiu com o período de estiagem, com baixas temperaturas e diminuição de fotoperíodo, e pela tendência natural de florescimento das forrageiras tropicais. De acordo com Gomide (1994), as gramíneas de clima tropical e semitropical distinguiram-se das demais pelo alto ponto de saturação de luz, pelo mais baixo ponto de compensação de $\mathrm{CO}_{2}$ e pela fotossíntese máxima a temperatura de 30 a $35^{\circ} \mathrm{C}$.

Os teores médios de MS observados nesta pesquisa foram superiores aos encontrados por Mari (2003) e Acunha \& Coelho (1997), na mesma espécie e em datas de rebrotação similares.

Comparando-se os teores médios de PB dentro dos cortes, com a aplicação de $180 \mathrm{~m}^{3}$ de DLS/ha/ano 1 x/ano fermentado, $180 \mathrm{~m}^{3} \mathrm{de}$ DLS/ha/ano $1 \mathrm{x} /$ ano in natura $\mathrm{e}$ $180 \mathrm{~m}^{3} \mathrm{de}$ DLS/ha/ano 2 x/ano fermentado (tratamentos 3 , 8 e 4, respectivamente), a planta forrageira demonstrou superioridade no primeiro corte, enquanto, no segundo corte, os tratamentos 3 e 8 superaram os demais. No

Tabela 3 - Porcentagem de MS (\%MS) em quatro cortes de capim-marandu fertirrigado com dejetos líquidos de suínos Table 3 - $\quad$ Average DM concentration (DM\%) in Brachiaria brizantha cv. Marandu fertirrigated with swine slurry; average data of four cuts

\begin{tabular}{|c|c|c|c|c|c|}
\hline \multirow[t]{2}{*}{$\begin{array}{l}\text { Tratamento } \\
\text { Treatment }\end{array}$} & \multicolumn{4}{|c|}{$\begin{array}{c}\text { Corte } \\
\text { Cut }\end{array}$} & \multirow[t]{2}{*}{$\begin{array}{l}\text { Média } \\
\text { Average }\end{array}$} \\
\hline & $1 \underline{\mathrm{o}}\left(1^{s t}\right)$ & $2 \underline{\underline{o}}\left(2^{n d}\right)$ & $3 \underline{\underline{o}}_{\left(3^{r d}\right)}$ & $4 \underline{\mathrm{o}}_{\left(4^{\text {th }}\right)}$ & \\
\hline 2 & $27,25 \mathrm{Bc}$ & $29,15 \mathrm{Bc}$ & $33,80 \mathrm{Bb}$ & $37,75 \mathrm{Ca}$ & $31,98 \mathrm{C}$ \\
\hline 3 & $22,90 \mathrm{Cc}$ & $26,35 \mathrm{Cb}$ & $32,77 \mathrm{Ba}$ & $34,45 \mathrm{Da}$ & $29,11 \mathrm{C}$ \\
\hline 4 & $24,60 \mathrm{Cd}$ & $27,85 \mathrm{Cc}$ & $30,95 \mathrm{Bb}$ & $36,45 \mathrm{Ca}$ & $29,96 \mathrm{C}$ \\
\hline 7 & $28,75 \mathrm{Bb}$ & $27,42 \mathrm{Cb}$ & $32,92 \mathrm{Ba}$ & $33,95 \mathrm{Da}$ & $30,76 \mathrm{C}$ \\
\hline 8 & $22,87 \mathrm{Cd}$ & $25,95 \mathrm{Cc}$ & $32,20 \mathrm{Bb}$ & $36,07 \mathrm{Ca}$ & $29,27 \mathrm{C}$ \\
\hline 9 & $33,32 \mathrm{Ac}$ & $40,22 \mathrm{Ab}$ & $39,17 \mathrm{Ab}$ & $48,65 \mathrm{Aa}$ & $40,34 \mathrm{~A}$ \\
\hline Média & $27,76 \mathrm{c}$ & $29,53 \mathrm{c}$ & $33,87 \mathrm{~b}$ & $37,07 \mathrm{a}$ & 32,05 \\
\hline
\end{tabular}


terceiro corte, os tratamentos não diferiram significativamente, exceto em relação ao tratamento controle, que apresentou menor teor de PB (Tabela 4).

Os teores de PB foram maiores no primeiro e segundo cortes, possivelmente em decorrência das melhores condições climáticas da época, pois normalmente condições melhores de precipitação e temperatura favorecem o desenvolvimento vegetativo. $\mathrm{O}$ teor de $\mathrm{PB}$, na maioria dos tratamentos, reduziu no decorrer do experimento, fato explicado pela diminuição da disponibilidade de nutrientes no solo, principalmente $\mathrm{N}$ (elemento essencial à síntese protéica). Esse fato deve ser associado às variações climáticas durante o período experimental, pois, de acordo com Monteiro et al. (2004), alterações na pluviosidade e na temperatura foram altamente determinantes na absorção de nutrientes e no crescimento das plantas forrageiras, o que resultou em concentrações não uniformes dos nutrientes no decorrer do ano. Esse autor enfatizou a influência da idade da planta e/ou do período de crescimento na absorção de nutrientes. O acúmulo na parte aérea das gramíneas obedeceu a uma curva sigmóide com uma fase de pequeno acúmulo no início do período de desenvolvimento seguida pela fase linear ascendente e, então, retornou à outra fase de pequenos acréscimos. Confirmando a teoria do autor em relação à interação tratamentos $\times$ cortes, o percentual de $\mathrm{PB}$ foi maior no primeiro corte em todos os tratamentos e decresceu nos sucessivos cortes.

Os maiores teores de PB foram observados na planta forrageira colhida no primeiro corte, provavelmente em decorrência da maior relação folha/colmo e, também, da época do ano com altas temperaturas e pluviosidade, aumentando a taxa de fotossíntese. $\mathrm{Na}$ interação tratamento $\times$ corte, detectou-se tendência de redução no teor de PB com a sucessão de cortes. Esse comportamento foi previsível e confirma os valores encontrados por outros autores (Mari, 2003; Narciso Sobrinho, 1998; Acunha \& Coelho, 1997; Andrade et al., 1994; Drudi \& Favoretto, 1987; Lavezzo et al., 1980; Santana \& Santos, 1983; Silveira et al., 1974).

Os teores médios de PB observados nas plantas forrageiras com a aplicação dos tratamentos 3 e 8 no primeiro corte foram de 13,17 e 13,77\%, respectivamente. Valores su periores foram observados por Silva (2004), que, utilizando quatro alturas diferentes de corte na $B$. brizantha cv. Marandu durante um ano, obteve variação de 11,3 a $13,7 \%$ PB. Nesta pesquisa, o valor médio entre as quatro diferentes épocas de corte foi de 9,6\% PB.

De modo geral, os maiores teores de FDN foram observados no segundo corte (Tabela 5), possivelmente em virtude da maior produção de MS neste corte.

Observou-se tendência de redução nos teores de FDN dos tratamentos em relação às diferentes épocas de corte. Variações estacionais nos teores de FDN também foram encontradas por Mari (2003) e Gerdes et al. (2000b), embora a ordem de decréscimos entre os tratamentos nesta pesquisa tenha sido alterada.

De acordo com Noronha (2001), mudanças na composição química foram ocasionadas pelas transformações estruturais dos tecidos da planta forrageira e pela translocação das substâncias nutritivas das folhas. Conseqüentemente, houve elevação dos constituintes estruturais, como fibras e lignina. Esse mesmo autor relatou ainda que houve decréscimo da PB e aumento do teor de MS e fibras à medida que a planta tendeu a completar seu ciclo fisiológico, fenômeno comum a todas espécies forrageiras, tendo em vista a redução na relação folha/colmo. Em

Tabela 4 - Teores de PB, com base na MS, em quatro cortes de capim-marandu fertirrigado com dejetos líquidos de suínos Table 4 - $\quad C P$ concentration (\% CP, DM basis) in Brachiaria brizantha cv. Marandu fertirrigated with swine slurry; average data of four cuts

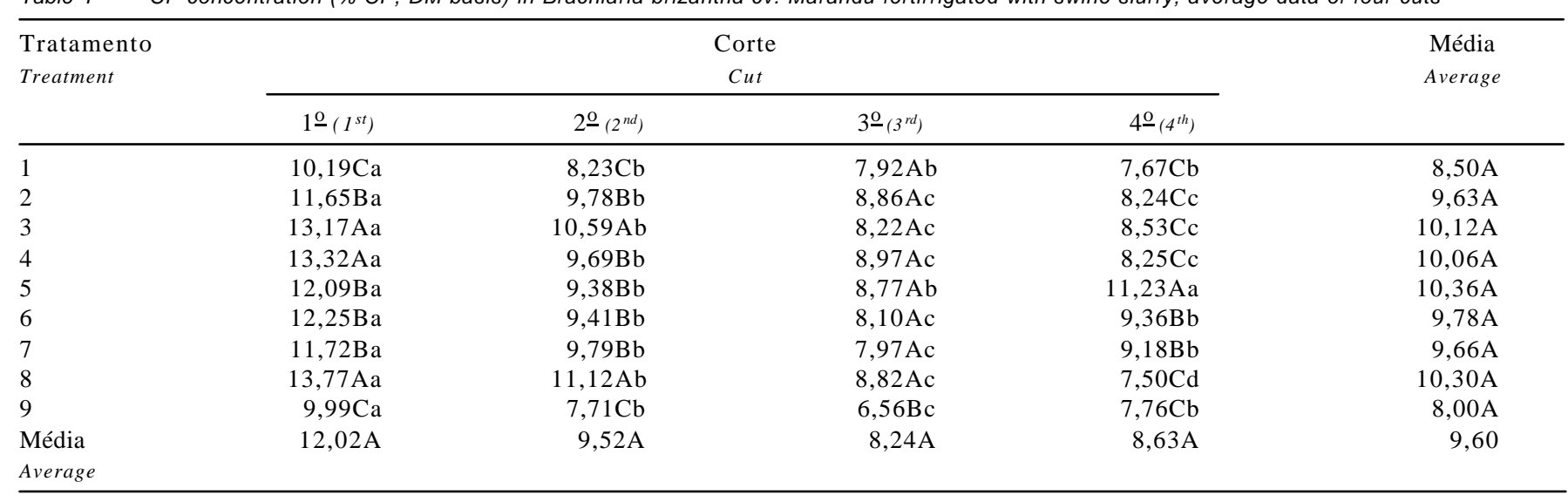


Tabela 5 - Teores de FDN (com base na MS) em quatro cortes de capim-marandu fertirrigado com dejetos líquidos de suínos Table 5 - Average NDF concentration (DM basis) in Brachiaria brizantha cv. Marandu fertirrigated with swine slurry; average data of four cuts

\begin{tabular}{lrrrr}
\hline $\begin{array}{l}\text { Tratamento } \\
\text { Treatment }\end{array}$ & \multicolumn{3}{c}{$\begin{array}{c}\text { Corte } \\
\text { Cut }\end{array}$} \\
\cline { 2 - 5 } & $1 \underline{\mathrm{o}}\left(1^{\text {st }}\right)$ & $2 \underline{\mathrm{o}}\left(2^{\text {nd }}\right)$ & $\left.3 \underline{\mathrm{o}}^{\text {rd }}\right)$ & \multicolumn{1}{c}{$\begin{array}{c}\text { Média } \\
\text { Average }\end{array}$} \\
\hline 1 & $63,80 \mathrm{Aa}$ & $66,30 \mathrm{Aa}$ & $59,50 \mathrm{Aa}$ & $62,30 \mathrm{Ab}$ \\
2 & $65,85 \mathrm{Aa}$ & $66,12 \mathrm{Aa}$ & $64,60 \mathrm{Ab}$ & $63,05 \mathrm{Ab}$ \\
3 & $63,20 \mathrm{Ab}$ & $68,60 \mathrm{Aa}$ & $61,80 \mathrm{Ab}$ & $62,30 \mathrm{Ab}$ \\
4 & $61,20 \mathrm{Ab}$ & $66,10 \mathrm{Aa}$ & $61,30 \mathrm{Aa}$ & $61,10 \mathrm{Ab}$ \\
5 & $63,65 \mathrm{Ab}$ & $64,80 \mathrm{Aa}$ & $58,00 \mathrm{Ab}$ & $62,00 \mathrm{Ab}$ \\
6 & $60,20 \mathrm{Ab}$ & $61,45 \mathrm{Aa}$ & $60,50 \mathrm{Aa}$ & $64,30 \mathrm{Ab}$ \\
7 & $57,50 \mathrm{Ab}$ & $63,20 \mathrm{Aa}$ & $60,30 \mathrm{Aa}$ & $62,20 \mathrm{Ab}$ \\
8 & $61,30 \mathrm{Ab}$ & $65,40 \mathrm{Aa}$ & $62,20 \mathrm{Aa}$ & $59,10 \mathrm{Ab}$ \\
9 & $60,40 \mathrm{Ab}$ & $64,20 \mathrm{Aa}$ & $60,20 \mathrm{Aa}$ & $64,00 \mathrm{Ab}$ \\
Média & $61,90 \mathrm{~b}$ & $65,13 \mathrm{a}$ & $59,82 \mathrm{~b}$ & $62,26 \mathrm{~b}$ \\
Average & & & 62,11 \\
\hline
\end{tabular}

Médias seguidas de letras diferentes, minúsculas na linha e maiúsculas na coluna diferem a $5 \%$ de probabilidade pelo teste Scott-Knott. Means followed by different letters, small within the same row and capital within the same column, differ $(P<0.05)$ by Scott-Knott test.

concordância com essa teoria, Zago \& Gomide (1982) relataram a especial relevância durante o verão quando a participação das hastes foi mais elevada e houve maior partição da energia da planta forrageira para perfilhos reprodutivos. Resultados semelhantes foram encontrados por Mari (2003), que obteve teores de 63,3\% no inverno e $77,6 \%$ no verão. Foi observada, também, situação semelhante à desta pesquisa em relação às estações do ano, pois o teor de FDN foi mais elevado no verão, seguido do outono e inverno. Valores inferiores foram encontrados por Silva (2004), em B. brizantha, ao utilizarem quatro alturas de corte do dossel, sendo que os percentuais variaram de 60,8 a $62,2 \%$

Van Soest (1994) destacou a importância dos valores de FDN para certificação da qualidade da planta forrageira e estabeleceu que valores de FDN superiores a $60 \%$ da MS associaram-se negativamente à capacidade de consumo voluntário da forragem pelos animais.

Os teores médios de FDA encontrados nos quatro cortes (Tabela 6) variaram de 21,20 a 34,20\% nos tratamentos 7 e 9 , representados pela aplicação de $180 \mathrm{~m}^{3} /$ ha $5 x /$ ano e testemunha, no primeiro e quarto cortes, respectivamente. Os menores valores de FDA foram observados nos tratamentos em que os dejetos foram utilizados na frequiência de $2 \mathrm{x} /$ ano (T4) e 5x/ano (T7) no primeiro corte. Esta variação dos teores de FDA nestes tratamentos possivelmente esteve associada às épocas do ano, ou seja, houve coincidência das melhores condições climáticas com a disponibilidade de nutrientes nesses tratamentos, enquanto, nos demais, os resultados foram similares.

De modo geral, os valores encontrados no primeiro corte (Tabela 4) foram inferiores aos observados por Barnabé (2001), que realizou cortes em intervalos de 33 dias e obteve variação no teor de FDA de 36,9 a $38 \%$ na MS com aplicações de $150 \mathrm{~m}^{3}$ de dejetos líquidos de suínos e testemunha, respectivamente.

No segundo e terceiro cortes, não foram observadas diferenças entre os tratamentos e, na quarta época, os maiores percentuais de FDA foram otidos com os tratamentos 1 e 9 (uso somente de calcário e testemunha), com teores de 32,95 e $34,20 \%$, respectivamente. Este resultado pode ser atribuído à menor disponibilidade de nutriente à planta nestes tratamentos, levando à senescência precoce em relação aos demais. De acordo com Noronha (2001), a falta de nutrientes para as plantas forrageiras provocou mudanças na composição química e elevou a proporção dos constituintes estruturais, principalmente lignina. Esse autor ainda relatou que, à medida que a planta tendeu a completar seu ciclo fisiológico, houve aumento dos constituintes indigeríveis, como a lignino-celulose.

Valores semelhantes foram encontrados por Silva (2004), que observou valores de 28,1 a 29,2\% FDA em quatro alturas de corte do dossel. Com valores superiores de FDA, Santos et al. (2003) observaram teores médios de $40,22 \%$ de FDA na B. brizantha aos 35 dias de idade. Entretanto, Rosa et al. (2004), trabalhando com B. brizantha fertirrigada com $200 \mathrm{~m}^{3} / \mathrm{ha} /$ ano de DLS e cortada em intervalos de 35 dias, observaram teores médios de FDA de 36,42\%.

No desdobramento dos tratamentos dentro das épocas de cortes, ficou evidenciado, principalmente no terceiro e quarto cortes, aumento do conteúdo de FDA em relação ao primeiro corte, em todos os tratamentos estudados, justificado pelas condições ambientais nas quais as plantas foram expostas durante o período experimental. O aumento no teor de FDA em todos tratamentos estudados 
era esperado, exatamente em virtude do percentual de MS da planta forrageira, visto que, em todos os tratamentos, verificou-se tendência de elevação dos teores da FDA na MS conforme se sucederam os cortes.

Os valores de DIVMS encontrados na planta forrageira estudada variaram de 45,31 (último corte) a 71,89\% (primeiro corte) (Tabela 7) e os maiores coeficientes foram verificados nas plantas dos tratamentos 3,4 e $8\left(180 \mathrm{~m}^{3} / \mathrm{ha} /\right.$ ano fermentado por 45 dias; e $180 \mathrm{~m}^{3} / \mathrm{ha} /$ ano - in natura respec tivamente). No segundo e terceiro cortes, não houve diferenças entre os tratamentos, sendo que, no quarto corte, observou-se superioridade no tratamento T2 (adubação química 100 - 40 - 60 de NPK) e naqueles com aplicação de DLS na última frequiência de adubação: $180 \mathrm{~m}^{3} / \mathrm{ha} / 3 \mathrm{x} / \mathrm{ano}$ (T5); $180 \mathrm{~m}^{3} / \mathrm{ha} / 4 \mathrm{x} /$ ano (T6) e $180 \mathrm{~m}^{3} / \mathrm{ha} / 5 \mathrm{x}$ (T7).
Valores maiores de DIVMS foram observados nas plantas dos tratamentos 3, 4 e 8 no primeiro corte, provavelmente em virtude da maior concentração de nutrientes no solo, principalmente na forma nitrogenada, quando utilizada a maior quantidade de DLS na primeira frequêencia de aplicação. Este resultado era esperado e está de acordo com os resultados observados para os teores de PB (Tabela 2), podendo ser uma relação positiva entre essas variáveis.

Gomide et al. (1969) encontraram correlação negativa da DIVMS com o teor de FDN $(r=-0,88)$ e positiva com teor de PB ( $r=0,89)$, ou seja, quanto maior o teor de PB maior a DIVMS e quanto menor a DIVMS maior a porcentagem de FDN.

$\mathrm{Na}$ interação tratamento $\times$ época de corte, o tratamento com aplicação adubação química 100 - 40 - 60 de NPK foi o

Tabela 6 - Teores da FDA (base MS) em quatro cortes de capim-marandu fertirrigado com dejetos líquidos de suínos Table 6 - Average ADF concentration (DM basis) in Brachiaria brizantha cv. Marandu fertirrigated with swine slurry; average data of four cuts

\begin{tabular}{|c|c|c|c|c|c|}
\hline \multirow[t]{2}{*}{$\begin{array}{l}\text { Tratamento } \\
\text { Treatment }\end{array}$} & \multicolumn{4}{|c|}{$\begin{array}{c}\text { Corte } \\
\text { Cut }\end{array}$} & \multirow[t]{2}{*}{$\begin{array}{l}\text { Média } \\
\text { Average }\end{array}$} \\
\hline & $1 \underline{\mathrm{O}}\left(1^{s t}\right)$ & $2 \underline{\underline{O}}\left(2^{n d}\right)$ & $3 \underline{0}\left(3^{r d}\right)$ & $4 \underline{\mathrm{O}}_{\left(4^{\text {th }}\right)}$ & \\
\hline 2 & $25,40 \mathrm{Ab}$ & $32,00 \mathrm{Aa}$ & $30,60 \mathrm{Aa}$ & $31,00 \mathrm{Ba}$ & $29,76 \mathrm{~A}$ \\
\hline 3 & $24,70 \mathrm{Ac}$ & $27,70 \mathrm{Ab}$ & $30,00 \mathrm{Aa}$ & $31,70 \mathrm{Ba}$ & $28,52 \mathrm{~A}$ \\
\hline 4 & $23,40 \mathrm{Bc}$ & $28,40 \mathrm{Ab}$ & $32,20 \mathrm{Aa}$ & $31,00 \mathrm{Ba}$ & $28,75 \mathrm{~A}$ \\
\hline 7 & $21,20 \mathrm{Bb}$ & $28,20 \mathrm{Aa}$ & $29,40 \mathrm{Aa}$ & $29,60 \mathrm{Ba}$ & $27,10 \mathrm{~A}$ \\
\hline 8 & $25,10 \mathrm{Ab}$ & $26,90 \mathrm{Aa}$ & $31,70 \mathrm{Aa}$ & $30,60 \mathrm{Ba}$ & $28,57 \mathrm{~A}$ \\
\hline 9 & $25,10 \mathrm{Ac}$ & $27,65 \mathrm{Ac}$ & $30,40 \mathrm{Ab}$ & $34,20 \mathrm{Aa}$ & $29,33 \mathrm{~A}$ \\
\hline Média & $24,63 \mathrm{c}$ & $28,74 b$ & $30,52 \mathrm{a}$ & $31,33 a$ & 28,80 \\
\hline Average & & & & & \\
\hline
\end{tabular}

Médias seguidas de letras diferentes, minúsculas na linha e maiúsculas na coluna diferem a $5 \%$ de probabilidade pelo teste Scott-Knott. Means followed by different letters, small within the same row and capital within the same column, differ $(P<0.05)$ by Scott-Knott test.

Tabela 7 - Coeficiente de digestibilidade in vitro da MS (DIVMS) em quatro cortes de capim-marandu fertirrigado com dejetos líquidos de suínos

Table 7- In vitro DM digestibility (IVDMD) of Brachiaria brizantha cv. Marandu fertirrigated with swine slurry; average data of four cuts

\begin{tabular}{|c|c|c|c|c|c|}
\hline \multirow[t]{2}{*}{$\begin{array}{l}\text { Tratamento } \\
\text { Treatment }\end{array}$} & \multicolumn{4}{|c|}{$\begin{array}{c}\text { Corte } \\
\text { Cut }\end{array}$} & \multirow[t]{2}{*}{$\begin{array}{l}\text { Média } \\
\text { Average }\end{array}$} \\
\hline & $1^{\mathrm{o}}\left(1^{s t}\right)$ & $2 \underline{\underline{o}}\left(2^{n d}\right)$ & $3^{\mathrm{o}}\left(3^{r d}\right)$ & $4^{\mathrm{o}}\left(4^{t h}\right)$ & \\
\hline 1 & $63,01 \mathrm{Ba}$ & $58,92 \mathrm{Aa}$ & $51,15 \mathrm{Ab}$ & $45,31 \mathrm{Bb}$ & $54,60 \mathrm{~A}$ \\
\hline 2 & $63,29 \mathrm{Ba}$ & $60,89 \mathrm{Aa}$ & $52,33 \mathrm{Ab}$ & $53,63 \mathrm{Ab}$ & $57,54 \mathrm{~A}$ \\
\hline 3 & $71,72 \mathrm{Aa}$ & $65,72 \mathrm{Aa}$ & $49,08 \mathrm{Ab}$ & $50,33 \mathrm{Bb}$ & $59,21 \mathrm{~A}$ \\
\hline 4 & $69,05 \mathrm{Aa}$ & $57,71 \mathrm{Ab}$ & $55,28 \mathrm{Ab}$ & $49,67 \mathrm{Bc}$ & $57,93 \mathrm{~A}$ \\
\hline 5 & $64,84 \mathrm{Ba}$ & $59,23 \mathrm{Aa}$ & $48,22 \mathrm{Ab}$ & $60,32 \mathrm{Aa}$ & $58,15 \mathrm{~A}$ \\
\hline 6 & $65,22 \mathrm{Ba}$ & $61,03 \mathrm{Aa}$ & $49,90 \mathrm{Ab}$ & $57,06 \mathrm{Aa}$ & $58,30 \mathrm{~A}$ \\
\hline 7 & $66,02 \mathrm{Ba}$ & $60,19 \mathrm{Aa}$ & $51,15 \mathrm{Ab}$ & $54,61 \mathrm{Ab}$ & $57,94 \mathrm{~A}$ \\
\hline 8 & $71,89 \mathrm{Aa}$ & $63,96 \mathrm{Ab}$ & $52,02 \mathrm{Ac}$ & $51,16 \mathrm{Bc}$ & $59,76 \mathrm{~A}$ \\
\hline 9 & $64,84 \mathrm{Ba}$ & $52,87 \mathrm{Ab}$ & $51,75 \mathrm{Ab}$ & $50,16 \mathrm{Bb}$ & $54,65 \mathrm{~A}$ \\
\hline Média & $66,54 a$ & $60,06 \mathrm{~b}$ & $51,18 c$ & $52,47 \mathrm{c}$ & 57,56 \\
\hline Average & & & & & \\
\hline
\end{tabular}


que proporcionou o percentual de menor variação do coeficiente de DIVMS na sucessão das épocas de cortes. Verificou-se ainda tendência de declínio na DIVMS à medida que ocorreram os cortes. Várias pesquisas têm comprovado que a proximidade da estação de inverno provoca declínio da DIVMS (Acunha \& Coelho, 1997; Gomide et al., 1985; Ribeiro et al., 1999; Ruggieri et al., 1995) em plantas forrageiras. Os coeficientes de DIVMS encontrados nesta pesquisa foram semelhantes aos obtidos na literatura. Assim como para os demais resultados discutidos, a variação ocorrida na DIVMS entre épocas de corte refletiu principalmente as variações ambientais, nutricionais e suas conseqüências.

Os valores de DIVMS obtidos nesta pesquisa foram semelhantes aos relatados por Mari (2003), média de 65,1\% (primavera), 63,8\% (verão/outono) e 66,6\% (inverno), e Silva (2004), também na mesma espécie, coeficientes de $66,6 \%$ nas alturas de corte de 10 e $20 \mathrm{~cm}$ e $62,7 \%$ e de 30 e $40 \mathrm{~cm}$.

\section{Conclusões}

A aplicação de $180 \mathrm{~m}^{3}$ de DLS/ha/ano, fermentados e in natura, no início do período chuvoso proporcionou, em comparação à adubação química, resultados melhores ou semelhantes para produção e qualidade do capim-marandu. Desta forma, os dejetos líquidos de suínos podem substituir de forma satisfatória a adubação química.

\section{Literatura Citada}

ACUNHA, J.B.V.; COELHO, R.W. Efeito da altura e intervalo de corte do capim-elefante-anão. I. Produção e qualidade da forragem. Pesquisa Agropecuária Brasileira, v.32, n.1, p.117-122, 1997.

ANDRADE, J.B.; FERRAI JR., E.; PEDREIRA, J.V.S. et al. Produção e qualidade dos fenos de Brachiaria decumbens e Brachiaria brizantha cv. Marandu sob três freqüências de corte. II - Qualidade do feno. Boletim da Indústria Animal, v.51, n.1, p.55-59, 1994.

BARNABÉ, M.C. Produção e composição bromatológica da Brachiaria brizantha cv. Marandu adubada com dejetos líquidos de suínos. Goiânia: Universidade Federal de Goiás, 2001. 67p. Dissertação (Mestrado em Medicina Veterinária) Universidade Federal de Goiás, 2001.

BOTREL, M.A.; ALViM, M.J.; MOZZER, O.L. Avaliação agronômica de gramíneas forrageira sob pastejo. Pesquisa Agropecuária Brasileira, v.22, n.9/10, p.1019-1025, 1987.

COMISSÃO DE FERTILIDADE DO SOLO DO ESTADO DE MINAS GERAIS - CFSEMG. Recomendações para uso de corretivos e fertilizantes em Minas Gerais. $5^{\text {a }}$ aproximação. Viçosa, MG, 1999. 359p.

DRUDI, A.; FAVORETTO, V. Influência, época e alutura de corte na produção e na composição química do capim- andropógon. Pesquisa Agropecuária Brasileira, v.22, n.11/12, p.12871292, 1987.

FERREIRA, D.F. SISVAR. Lavras: UFLA (Departamento de Ciências Exatas - DEX), 2000. (CD-ROM).
GERDES, L.; WERNER, J.C.; COLOZZA, M.T. et al. Avaliação de características e morfológicas das gramíneas forrageiras Marandu, Setária e Tanzânia aos 35 dias de crescimento nas estações do ano. Revista Brasileira de Zootecnia, v.29, n.4, p.947-954, 2000a.

GERDES, L.; WERNER, J.C.; COLOZZA, M.T. et al. Avaliação de características de valor nutritivo das gramíneas forrageiras Marandu, Setária e Tanzânia nas estações do ano. Revista Brasileira de Zootecnia, v.29, n.4, p.955-963, 2000b.

GOERING, H.K.; Van SOEST, P.J. Forage fiber analysis (apparatus, reagents, procedures, and some applications). Washington: United States Department of Agriculture Agricultural Research Service, 1970. (Agricultural Handbook, 379).

GOMIDE, J.A.; CÂNDIDO, M.J.D.; ALEXANDRINO.E. As interfaces solo - planta-animal da exploração da pastagem. In: SIMPÓSIO DE FORRAGICULTURA E PASTAGENS, 2003, Lavras. Anais... Lavras: Universidade Federal de Lavras, 2003. p.267.

GOMIDE, J.A.; OBEID, J.A.; QUEIROZ, D.S. et al. Freqüência de cortes, espaçamento entre fileiras e adubação de capim colonião (Panicum maximum Jacques) e capim Jaraguá (Hyparrhenia rufa, (Nees) Stapf.). Revista da Sociedade Brasileira de Zootecnia, v.14, n.3, p.326-337, 1985

GOMIDE, J.A.; OBEID, J.A.; RODRIGUES, L.R.A. Fatores morfosisiológicos de rebrota do capim-colonião Panicum maximum. Revista Brasileira de Zootecnia, v.8, p.532-562, 1969.

GOMIDE, J.A. Fisiologia do crescimento livre de plantas forrageiras. In: SIMPÓSIO SOBRE MANEJO DA PASTAGEM, 20., 1994, Piracicaba. Anais... Piracicaba: Fundação de Estudos Agrários Luiz de Queiroz, 1994. p.1-14.

HILL, J. The remobilization of nutrient from leaves. Journal Plant Nutrition, v.2, p.407-444, 1980.

HORWTZS, W. Official methods of analyses of the association of the official analytical chemist. 12.ed. Washington: AOAC, 1975. 1094p.

LAVEZZO, W.; SILVEIRA, A.C.; GONÇALEZ, D.A. et al. Efeito da idade da planta ao primeiro corte sobre a produção, composição bromatológica e alguns aspectos morfológicos da Brachiaria decumbens, Stapf. Revista Brasileira de Zootecnia, v.9, n.4, p.656-672, 1980.

LUPINACCI, A.V. Reservas orgânicas, índice de área foliar e produção de forragem em Brachiaria brizantha cv. Marandu submetida a intensidades de pastejo por bovinos de corte. Piracicaba: Escola Superior de Agricultura Luiz de Queiroz, 2002. 174p. Dissertação (Mestrado em Agronomia - Ciência Animal e Pastagens) - Escola Superior de Agricultura Luiz de Queiroz, 2002.

MARI, L.J. Intervalo entre cortes em capim-Marandu (Brachiaria brizantha (hochts. Ex a. Rick) Stapf cv. Marandu): produção, valor nutritivo e perdas associadas à fermentação da silagem. Piracicaba: Escola Superior de Agricultura Luiz de Queiroz, 2003. 138p. Dissertação (Mestrado em Agronomia - Ciência Animal e Pastagens) - Escola Superior de Agricultura Luiz de Queiroz, 2003.

MONTEIRO, F.A.; VENDDEMIATTI, J.A.; SILVEIRA, C.P. Concentração de enxofre e relação $\mathrm{N}: \mathrm{S}$ em folhas diagnósticas de capim-Tanzânia suprido de doses de nitrogênio e enxofre. In: REUNIÃO ANUAL DA SOCIEDADE BRASILEIRA DE ZOOTECniA, 41., 2004, Campo Grande. Anais... Campo Grande: Sociedade Brasileira de Zootecnia, 2004. (CD-ROM).

NARCISO SOBRINHO, J. Silagem de capim-elefante (Pennisetum purpureum Schum.) em três estádios de maturidade, submetido ao emurchecimento. Piracicaba: Escola Superior de Agricultura Luiz de Queiroz, 1998. 105p. Dissertação (Mestrado em Agronomia - Ciência Animal e Pastagens) Escola Superior de Agricultura Luiz de Queiroz, 1998.

NORONHA, J.F.; ROSA, B. Produção de leite no sistema de rotação de pastagem: viabilidade técnica e econômica. 
Goiânia: Universidade Federal de Goiás, 2001. p.245-273. (Coleção Quíron, Série Agros, 3).

NUNES, S.G.; BOOCK, A.; PENTEADO, M.I.O. et al. Brachiaria brizantha cv. Marandu. Campo Grande: EMBRAPA - CNPGC, 1985. 31p. (Documentos, 21).

RIBEIRO, K.G.; GOMIDE, J.A.; PACCIULLO, D.S.C. Adubação nitrogenada do capim-elefante cv. Mott. 2. Valor nutritivo ao atingir 80 e $120 \mathrm{~cm}$ de altura. Revista Brasileira de Zootecnia, v.28, n.6, p.1194-1202, 1999.

ROLIM, F.A. Efeito da maturidade sobre a produção e o valor nutritivo dos capins Braquiária (Brachiaria decumbens, Stapf), Estrela Cynodon plectostachyus, (K. Schum) Pilger e Rhodes (Chloris gayana, Kunth cultivar Callide). Piracicaba: Escola Superior de Agricultura "Luiz de Queiroz", 1976. 117p. Dissertação (Mestrado em Agronomia - Ciência Animal e Pastagens) - Escola Superior de Agricultura "Luiz de Queiroz", 1996.

ROSA, B.; NAVES, M.A.T.; RAMOS, C.S. et al. Utilização de dejetos líquidos de suínos na produção e composição químicobromatológica do capim Braquiarão "Brachiaria brizanthacv. Marandu". In: REUNIÃO ANUAL DA SOCIEDADE BRASILEIRA DE ZOOTECNIA, 40., 2004, Campo Grande. Anais... Campo Grande: Sociedade Brasileira de Zootecnia. (CD-ROM).

RUGGIERI, A.C.; FAVORETTO, V.; MALHEIROS, E.B. Efeito de níveis de nitrogênio e regimes de corte na distribuição, na composição bromatológica e na digestibilidade "in vitro" da matéria seca da Brachiaria brizantha (Hochst) Stapf. Cv. Marandu. Revista Brasileira de Zootecnia, v.24, n.1, p.2131, 1995.

SANTANA, J.R.; SANTOS, C.L. Efeito do parcelamento de nitrogênio e intervalos entre cortes sobre a produção de matéria seca e de proteína bruta de Setaria anceps (Schum). Stapf. \& Hub cv. Kaszungula. Revista Brasileira de Zootecnia, v.12, n.3, p.522-534, 1983 .
SANTOS, I.P.A.; PINTO, J.C.; SIQUEIRA, J.O. et al. Resposta a fósforo, micorriza e nitrogênio de braquiarão e amendoim forrageiro consorciados. 1. Rendimentos de matéria seca da parte aérea e da raiz. Ciências Agrotécnicas, v.25, n.5, p.1206-1215, 2003.

SBRISSIA, A.F. Morfogênese, dinâmica do perfilhamento e do acúmulo de forragem em pastos de capim-Marandu sob lotação contínua. Piracicaba: Escola Superior de Agricultura "Luiz de Queiroz", 2004. 199p. Tese (Doutorado em Agronomia - Ciência Animal e Pastagens) - Escola Superior de Agricultura "Luiz de Queiroz", 2004.

SILVA, D.J.; QUEIROZ, A.C. Análise de alimentos: métodos químicos e biológicos. 3.ed. Viçosa, MG: Universidade Federal de Viçosa, 2002. 235p.

SILVA, S.C. Fundamentos para o manejo do pastejo de plantas forrageiras dos gêneros Brachiaria e Panicum. In: SIMPÓSIO SOBRE MANEJO ESTRATÉGICO EM PASTAGEM, 2004, Viçosa, MG. Anais... Viçosa, MG: Universidade Federal de Viçosa, 2004. p.346-385.

SILVEIRA, A.C.; TOSI, H.; FARIA, V.P. et al. Efeito da maturidade sobre a composição químico-bromatológica do capim Napier (Pennisetum purpureum, Schum). Revista da Sociedade Brasileira de Zootecnia, v.3, n.2, p.158-171, 1974.

Van SOEST, P.J. Nutritional ecology of the ruminat. 2.ed. Ithaca: Cornell University Press, 1994. 476p.

ZAGO, C.P.; GOMIDE, J.A. Valor nutritivo do capim-colonião, submetido a diferentes intervalos de corte, com e sem adubação de reposição. Revista da Sociedade Brasileira de Zootecnia, v.11, n.3, p.512- 528, 1982. 